\title{
THEORETICAL STUDY OF CHANGE IN AROMATICITY OF AROMATIC RINGS UPON COMPLEXATION WITH A CATION/ANION.
}

Jesús Rodríguez-Otero, ${ }^{\mathrm{a},{ }^{*}}$ Enrique M. Cabaleiro-Lago, ${ }^{\mathrm{b}}$ Angeles Peña-Gallego ${ }^{\mathrm{a}}$ and M. Merced Montero-Campillo. ${ }^{a}$

${ }^{a}$ Departamento de Química Física, Facultade de Química, Universidade de Santiago de Compostela, Avda. das Ciencias s/n, 15782 Santiago de Compostela, Galicia, Spain.

${ }^{\text {b}}$ Departamento de Química Física, Facultade de Ciencias, Universidade de Santiago de Compostela, Campus de Lugo, Avda. Alfonso X El Sabio s/n 27002 Lugo, Galicia, Spain.

e-mail: qftjesus@usc.es

\begin{abstract}
NICS methodology has been applied to study the change in aromaticity in several aromatic rings (benzene, pyrrol, triazine, hexafluorobenzene) on complexation with several ions $\left(\mathrm{Li}^{+}\right.$, $\left.\mathrm{Na}^{+}, \mathrm{K}^{+} . \mathrm{F}^{-}, \mathrm{Cl}^{-}\right)$. For this purpose all the isolated and complexed rings have been optimized at the MP2/6-31++G(d,p) level of theory. Using GIAO method to calculate NICS values, the change in aromaticity on complexation was assessed. From the calculated values of NICS(1) and $\operatorname{NICS}_{Z Z}(1)$ the only relevant conclusion is that a very small change in aromaticity takes place; however, no trend is observed. Moreover, a large discrepancy between the results from the two aromatic descriptors is found.
\end{abstract}




\section{Introduction}

Intermolecular interactions involving aromatic rings are important processes in both chemical and biological recognition. Their understanding is essential for the rational designs of drugs and other new functional materials. ${ }^{1}$ Up to now, not many studies have analyzed the change in aromaticity of aromatic rings on complexation with a cation or an anion. Guell et al. ${ }^{2}$ found that interaction of $\mathrm{Li}^{+}$with fused PAHs (polycyclic aromatic hydrocarbons) occurs preferentially in the $\pi$ electron richer rings, which in most cases are also the most aromatic. Moreover, on complexation, there was a clear but small reduction of the aromaticity of the ring directly interacting with the lithium cation. This analysis was carried out mainly with $\mathrm{HOMA}^{3}$ (harmonic oscillator model of aromaticity) and, especially, with NICS ${ }^{4}$ (nucleusindependent chemical shift) aromaticity descriptors since in most cases, changes in the electronically based $\mathrm{PDI}^{5}$ (para-delocalization index) and $\mathrm{FLU}^{6}$ (aromatic fluctuation index) indices were almost irrelevant.

Several theoretical studies of Deyà et al. ${ }^{7-9}$ have analyzed the interactions between an aromatic ring and a cation or an anion. Although these studies were more focused on energetics, physical nature of the cation/anion- $\pi$ interaction and charge transfer than on analysis of aromaticity change, the results based in NICS calculations pointed to a decrease of aromaticity upon complexation with cations and an increase on complexation with anions. However, in this general behaviour these authors found some exception and, moreover, some observed trends were not fully expected.

In order to deal with this topic in depth, in the present work we present a comprehensive analysis of the change in aromaticity of aromatic rings on complexation with a cation or an anion. The chosen aromatic rings were benzene, triazine, pyrrol and hexafluorobenzene; the ions were $\mathrm{Li}^{+}, \mathrm{Na}^{+}, \mathrm{K}^{+}, \mathrm{F}^{-}$and $\mathrm{Cl}^{-}$.

\section{Computational details}

The geometry of each stationary point was optimized at the MP2 level with the $6-31++G(d, p)$ basis set. For complexes, only the structure where the ion interacts with the $\pi$ cloud has been taken into account. In some cases, this is not the most stable of the possible structures (for example, cations interact in a more favourable way with the nitrogen atom of the ring plane in pyrrol and triazine). However, the goal of our study is the interaction $\pi$-ion.

For the complexes the interaction energies were calculated at the same level with correction for the basis set superposition error (BSSE) using the Boys-Berrnardi counterpoise method. ${ }^{10}$ 
To evaluate the aromaticity of the aromatic rings and their complexes with ions, the NICS criterion has been used. ${ }^{4}$ This method is based on the negative of the magnetic shielding computed at the centre of the ring. Significant negative values imply aromaticity (diatropic ring current) and positive values correspond to antiaromaticity (paratropic ring current). As shown by Lazzeretti and Aihara, ${ }^{11-13}$ NICS values at the geometrical centre of the ring (NICS $(0))$ contain important spurious contributions from the in-plane tensor components that are not related to aromaticity. NICS(1) ( $1 \AA$ above/below the plane of the ring) essentially reflects $\pi$ effects and it is a better indicator of the ring current than the value at the centre, because at $1 \AA$ the effects of the local $\sigma$-bonding contributions are diminished. ${ }^{11,14,15}$ The outof-plane component of the NICS(1) value, $\operatorname{NICS}_{Z Z}(1)$, was also calculared. This index is considered to better reflect the $\pi$-electron effects and therefore is probably an even better descriptor of aromaticity. ${ }^{15}$

For complexed species, NICS(1) values were calculated below the centre of the ring, on the opposite face to the ion.

Using the MP2 optimized structures, NICS values were calculated at the HF/6-31++G(d,p) level using the GIAO (gauge-independent atomic orbital) method. ${ }^{16}$ Calculations were carried out with Gaussian03 program. ${ }^{17}$

\section{Results and discussion}

Figure 1 shows the complexes studied in the present work. Only triazine (TZN) is able to get a favourable interaction both with cations and anions. This fact was already previously explained for Garau et al. ${ }^{9}$ which showed that molecules with negligible permanent quadrupole moment values, $Q_{z z}$, can interact favourably with either cations or anions, and it is expected that the strength of the interaction would be comparable. Table 1 shows that TZN ( $\left.Q_{z z}=+0.90 \mathrm{~B}\right)^{18}$ form complexes with cations and anions, although the interaction energies are rather small (ranging from 2 to $10 \mathrm{kcal} / \mathrm{mol}$ ). Benzene (BEN) and pyrrol (PYR) have substantial negative $Q_{z z}$ values: -7.99 and $-8.84 \mathrm{~B}$, respectively. ${ }^{18}$ So, these two aromatic rings form complexes only with cations, but showing large interactions energies (ranging from 15 to $37 \mathrm{kcal} / \mathrm{mol})$. 

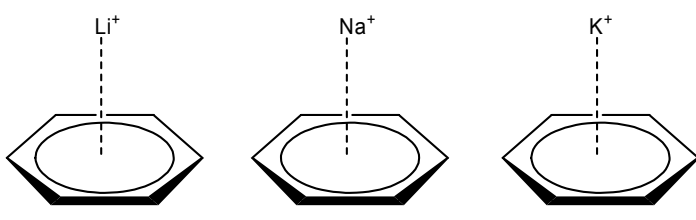

BENZENE (BEN)
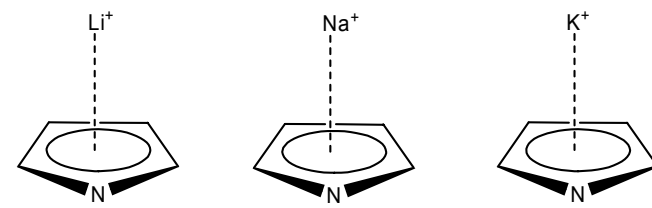

PYRROL (PYR)
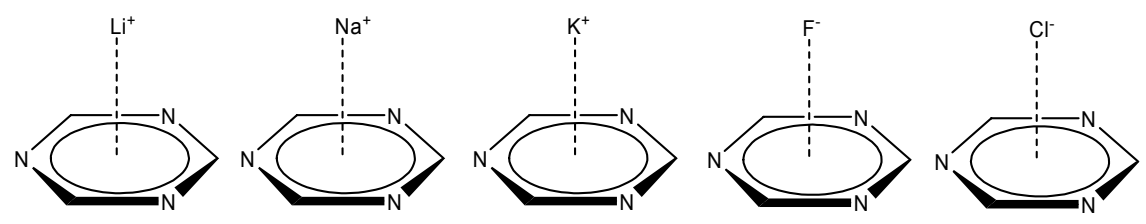

TRIAZINE (TZN)
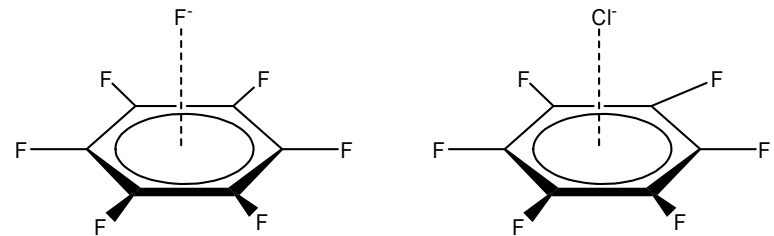

HEXAFLUOROBENZENE

(HFB)

Figure 1. Complexes studied in the present work

Table 1. Interaction energies including BSSE correction $(\Delta E, \mathrm{kcal} / \mathrm{mol})$ at the MP2/6-31++G(d,p) level, equilibrium distances $\left(R_{e}, \AA\right)$, between cation/anion and the centre of the ring and Mulliken/MerzKollman charges $(q, e)$ of the ion in the complex

\begin{tabular}{|c|c|c|c|c|}
\hline & $\Delta E$ & $R_{e}$ & $q$ (Mull) & $q(\mathrm{MK})$ \\
\hline $\mathrm{BEN} \mathrm{Li}^{+}$ & -33.35 & 1.938 & +0.41 & +0.66 \\
\hline $\mathrm{BEN}-\mathrm{Na}^{+}$ & -21.12 & 2.425 & +0.74 & +0.77 \\
\hline $\mathrm{BEN}-\mathrm{K}^{+}$ & -15.13 & 2.895 & +0.98 & +0.82 \\
\hline PYR-Li ${ }^{+}$ & -37.08 & 1.978 & +0.46 & +0.66 \\
\hline PYR-Na ${ }^{+}$ & -24.26 & 2.506 & +0.82 & +0.78 \\
\hline PYR-K ${ }^{+}$ & -17.91 & 2.879 & +1.00 & +0.82 \\
\hline TZN-Li ${ }^{+}$ & -6.17 & 2.210 & +0.65 & +0.78 \\
\hline $\mathrm{TZN} \mathrm{Na}^{+}$ & -2.63 & 2.717 & +0.84 & +0.85 \\
\hline TZN-K & -1.61 & 3.130 & +0.97 & +0.89 \\
\hline $\mathrm{TZN}-\mathrm{F}^{-}$ & -9.57 & 2.583 & -0.93 & -0.84 \\
\hline $\mathrm{TZN}-\mathrm{Cl}^{-}$ & -5.22 & 3.220 & -0.96 & -0.90 \\
\hline HFB-F' & -18.74 & 2.570 & -0.91 & -0.82 \\
\hline $\mathrm{HFB}^{-\mathrm{Cl}^{-}}$ & -12.87 & 3.160 & -0.88 & -0.86 \\
\hline
\end{tabular}


Hexafluorobenzene (HFB) represents the opposite case: a large positive $Q_{z z}$ value $(+9.50 \mathrm{~B})^{19}$, therefore the interaction energies are rather large (ranging from 13 to $19 \mathrm{kcal} / \mathrm{mol}$ ), but only with anions. All these considerations have been previously treated for other authors ${ }^{20}$, so we will concentrate only on aromaticity aspects.

Table 2 show the change in aromaticity upon complexation, calculated by NICS(1) and $\operatorname{NICS}_{Z Z}(1)$, considering $\triangle \mathrm{NICS}=\mathrm{NICS}$ (complex) - NICS(isolated ring). The analysis of this table is totally fruitless and neither any conclusion nor any trend can be extracted from the results.

Table 2. Change in aromaticity upon complexation, calculated by NICS(1) and $\operatorname{NICS}_{z z}(1)$ (in ppm), considering $\triangle \mathrm{NICS}=\mathrm{NICS}$ (complex) - NICS(isolated ring) .

\begin{tabular}{|c|c|c|}
\hline & $\Delta \mathrm{NICS}(1)$ & $\Delta \mathrm{NICS}_{\mathrm{ZZ}}(1)$ \\
\hline $\mathrm{BEN}^{-\mathrm{Li}^{+}}$ & +0.16 & +0.29 \\
\hline $\mathrm{BEN}-\mathrm{Na}^{+}$ & +0.41 & -0.66 \\
\hline BEN-K & +0.09 & -1.52 \\
\hline PYR-Li ${ }^{+}$ & -0.19 & -0.03 \\
\hline PYR-Na ${ }^{+}$ & +0.13 & -0.65 \\
\hline PYR-K & -0.18 & -1.29 \\
\hline TZN-Li ${ }^{+}$ & +0.46 & -0.11 \\
\hline TZN-Na ${ }^{+}$ & +0.56 & -0.41 \\
\hline TZN-K ${ }^{+}$ & +0.10 & -0.86 \\
\hline TZN-F' & +0.02 & -0.13 \\
\hline $\mathrm{TZN}-\mathrm{Cl}^{-}$ & -0.32 & -0.99 \\
\hline HFB-F ${ }^{-}$ & -0.65 & -1.18 \\
\hline $\mathrm{HFB}^{-\mathrm{Cl}^{-}}$ & -0.81 & -1.60 \\
\hline
\end{tabular}

According to $\mathrm{NICS}_{\mathrm{ZZ}}(1)$ values, only for the $\mathrm{BEN}-\mathrm{Li}^{+}$complex a decrease of aromaticity is observed; for all the rest of complexes (with cations or anions) an increase of aromaticity is obtained. Moreover, in a series $\left(\mathrm{Li}^{+}-\mathrm{Na}^{+}-\mathrm{K}^{+}\right.$or $\left.\mathrm{F}^{-}-\mathrm{Cl}^{-}\right)$this increase systematically rise with the size of cation/anion. So, the effect for potassium complexes is always much larger than for lithium complexes. This fact is not much reasonable, since as it was previously stated ${ }^{9}$, the electrostatic component is essential in the cation/anion- $\pi$ interaction. Table 1 shows that charge transfer for lithium complexes is substantially larger than for potassium complexes, so it would be expected a larger change in aromaticity for the lithium complexes.

NICS(1) values are totally inconsistent with those of their out-of-plane component: no comparison between them can be performed. In this case, only a general trend could roughly 
be observed. According to this trend (already stated for Deyà et al. $^{7-9}$ ), a decrease of aromaticity is observed on complexation with cations and an increase on complexation with anions. However, this trend shows too many exceptions, (especially for pyrrol complexes) to be considered reliable. So, in summary, neither $\operatorname{NICS}_{Z Z}(1)$ nor NICS(1) supply any useful information to understand the change in aromaticity upon complexation. Which can be the reasons for the inconsistency of NICS results?

A first consideration is that the change in aromaticity seems to be not much significant: as much of about $1 \mathrm{ppm}$. Probably, NICS calculations do not supply enough reliability to account for a so small effect.

The second consideration is that there are a number of problems with the NICS approach. ${ }^{12}$ One of them is the lack of a reference. Since one cannot simply turn off the current to get a non-aromatic NICS reference value, one must either rely on NICS values for other molecules, or chemical intuition. Neither approach is fully satisfactory in terms of reliability. In general, the NICS values are not transferable from one group of molecules to another. ${ }^{21}$ They can be used as a relative measure of the aromaticity for closely related molecules. That is, to compare NICS values for structures with significant differences in structure is not a reliable procedure. But, this is precisely our problem: we are performing a comparison between two structures with important differences (the isolated ring and the complexed ring). Therefore, it is not surprising that results of table 2 were so discouraging.

\section{Conclusions}

A first general consideration is that both our results and previous results of other authors show up that for aromatic rings the change in aromaticity upon complexation with a cation/anion is very small. So, after complexation the aromatic ring preserve its aromaticity basically unchanged. Therefore, the variation in aromaticity is a rather slight phenomenon and consequently, its study is not an easy task. A previous work ${ }^{2}$ showed that among several aromaticity descriptors only NICS (and to a lesser extent, HOMA) was able to generate consistent results. However, our calculations show that application of NICS to study the change in aromaticity of BEN, PYR, TZN and HFB on complexation with a cation/anion, lead to absolutely incoherent results. This failure of NICS results is a consequence of the very small change in aromaticity and the inherent limitations of NICS methodology. 


\section{References}

[1] E.A. Meyer, R.K. Castellano, F.Diederich, Angew. Chem. Int. Ed. 42 (2003) 1210.

[2] M. Güell, J. Poater, J.M. Luis, O. Mó, M. Yañez, M. Solà, ChemPhysChem 6 (2005) 2552.

[3] J. Kruszewski, T.M. Krygowski, Tetrahedron Lett. 13 (1972) 3839.

[4] P.v.R. Schleyer, C. Maerker, A. Dransfeld, H. Jiao, N.J.R.v.E. Hommes, J. Am. Chem. Soc. 118 (1996) 6317.

[5] J. Poater, X. Fradera, M. Durán, M. Solà, Chem. Eur. J. 9 (2003) 400.

[6] E. Matito, M. Durán, M. Solà, J. Chem. Phys. 122 (2005) 014109.

[7] D. Quiñonero, C. Garau, A. Frontera, P. Ballester, A. Costa, P.M. Deyà, Chem. Phys. Lett. 359 (2002) 486.

[8] C. Garau, A. Frontera, D. Quiñonero, P. Ballester, A. Costa, P.M. Deyà, Chem. Phys. Lett. $392(2004) 85$.

[9] Garau, A. Frontera, D. Quiñonero, P. Ballester, A. Costa, P.M. Deyà, J. Phys. Chem. A 108 (2004) 9423.

[10] S.B. Boys, F. Bernardi, Mol. Phys. 19 (1970) 553.

[11] P. Lazzereti, in: J.W. Emsley, J. Feeney, L.H. Sutcliffe (Eds.), Progress in Nuclear Magnetic Resonance Spectroscopy Vol. 36, Elsevier, Amsterdam, 2000, p 1.

[12] P. Lazzeretti, Phys. Chem. Chem. Phys. 6 (2004) 217.

[13] J. Aihara, Chem. Phys. Lett. 365 (2002) 34.

[14] P.v.R. Scheleyer, M. Manoharan, Z.X. Wang, B. Kiran, H.J. Jiao, R. Puchta, N.J.R.v.E. Hommes, Org. Lett. 3 (2001) 2465.

[15] C. Corminboeuf, T. Heine, G. Seifert, P.v.R. Schleyer, J. Weber, Phys. Chem. Chem. Phys. 6 (2004) 273.

[16] K. Wolinski, J.F. Hilton, P. Pulay, J. Am. Chem. Soc. 112 (1990) 8251.

[17] M.J. Frisch et al., Gaussian 03 (Revision B.03), Gaussian, Inc., Pittsburgh, PA, 2003.

[18] R.J. Doerksen, A.J. Thakkar, J. Phys. Chem. A 103 (1999) 10009.

[19] J.H. Williams, Acc. Chem. Res. 26 (1993) 593.

[20] D. Quiñonero, A. Frontera, C. Garau , P. Ballester, A. Costa, P.M. Deyà, ChemPhysChem 7 (2006) 2487 (and references therein).

[21] M. Bühl, Chem. Eur. J., 4 (1998) 734. 